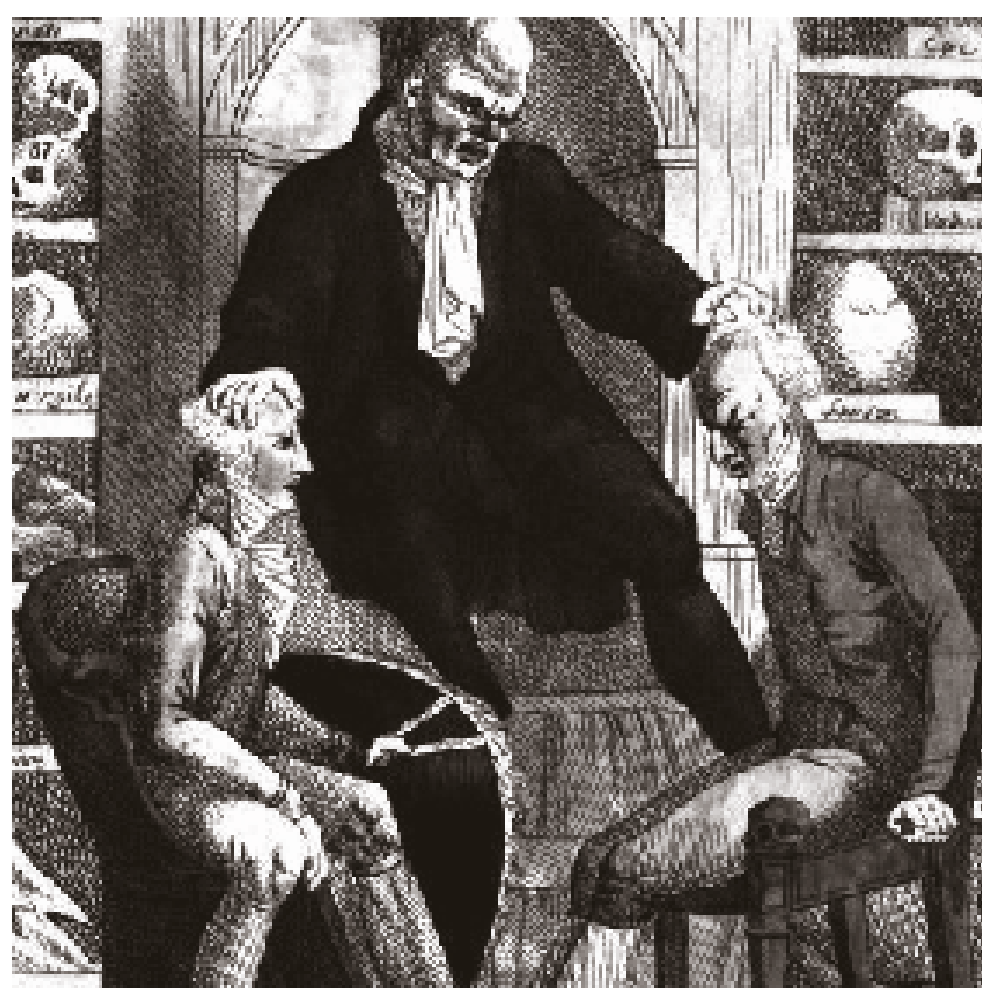




\title{
LOS ORÍGENES \\ DE LA PSICOLOGÍA
}

\author{
Dr. Ramón León Donayre \\ Docente de la Escuela de Posgrado UMCH
}

\section{Resumen}

Los orígenes de la psicología, las corrientes que influyeron en ella, sus relaciones con las artes y con las ciencias sociales, así como sus crisis son tratados brevemente en esta comunicación. La psicología cientííca no aparece en el aire sino es el resultado de un largo proceso de desarrollo, que es influenciado por los cambios sociales.

Palabras clave: psicología - desarrollo histórico

\section{Summary}

The origins of psychology, the philosophical schools, her relationships with the arts and the social sciences, and her crisis are briefly presented in this communication. Scientific psychology is not raised as a isolated science, but she has a large developmental process, which was influenced by the social changes.

Key words: psychology - historical development

Ciencia surgida en el último cuarto del siglo XIX y establecida definitivamente en el escenario cultural del siglo $X X$ y de lo que va del $X X \mid$, la psicología es también una profesión que ha logrado demostrar su utilidad en la comprensión de algunos de los grandes problemas sociales. Illouz (2007) ha descrito cómo es que los psicólogos progresivamente ampliaron su área de acción, comenzando por la infancia, siguiendo con la educación, prosiguiendo con la familia, para después intervenir en dominios como el de las organizaciones, las relaciones internacionales, el deporte. Esto es lo que se ha dado en denominar psicologización definida como "el vocabulario y los esquemas explicatorios psicológicos que han ingresado a campos que supuestamente no pertenecen a los terrenos tradicionales teóricos y prácticos de la psicología" (De Vos, 2012, p. I). 
Esta carrera triunfal de la psicología no ha ocurrido ciertamente por obra del azar.

La imagen del psicólogo como alguien poseedor de poderes casi mágicos que supuestamente le hacían factible penetrar sin mayores problemas en la realidad subjetiva del otro, ha cedido su lugar a la de un profesional entrenado en técnicas de entrevista, conocedor del empleo, calificación e interpretación de inventarios de personalidad y de tests que evalúan capacidades y características psicológicas, y con destrezas para diseñar y llevar a cabo de modo serio trabajos de investigación.

Esa imagen del profesional que posee un conjunto de conocimientos provenientes de rigurosos trabajos de laboratorio o de índole psicométrica, que le permite ofrecer una contribución significativa a la sociedad, es la que ha permitido esa carrera triunfal.

Las grandes figuras de la primera hora de la psicología como ciencia (por ejemplo, Wilhelm Wundt, 1832-1920, Hermann Ebbinghaus, 1850-1909, o Georg Elias Müller, 1850-1934) jamás pensaron que ella habría de extender su campo de acción al medio ambiente (psicología ambiental), a la justicia (psicología jurídica) o la selección, clasificación y promoción del personal (psicología organizacional), para señalar solo tres áreas de la vida social. Tampoco pensaron, por cierto, en que existiría algo como lo que es hoy día la psicoterapia. De volver a la vida y ver lo que hoy es la psicología, sin duda alguna se sorprenderían.

Wundt, con acendrada inclinación hacia la filosofía, no aprobaría que lo que él consideraba una ciencia de laboratorio' fuera hoy una profesión en la cual al lado de quienes trabajan en laboratorios y se llaman a sí mismos psicólogos experimentales, estén otros que, trabajando con pruebas psicológicas, con focus groups, o desenvolviéndose en el campo del counseling o de la psicoterapia, reclaman también para sí la misma denominación.

No nos engañemos, sin embargo: no todo es color de rosa en el mundo de la psicología. Quien se acerque con mirada crítica a ella podrá reconocer fracturas, resquebrajamientos, dilemas y problemas conceptuales, y hasta amenazas que tienen una dimensión preocupante.

i La psicología como ciencia surgió circunscrita a las cuatro paredes de un laboratorio y a un tema, el de la sensación y la percepción. Quien revise la producción escrita de Wundt, el así llamado padre de la psicología experimental, podrá verificar que entre los 1870 y 1890 ese fue el gran tema de su interés, y en el que volcó su legendaria capacidad de trabajo.

Pero fue el mismo Wundt quien, a partir de la última década del siglo XIX incursiona en lo que hoy llamaríamos psicología social. Por esa misma década y, en realidad no tan lejos de Leipzig, para ser más precisos en Viena, un médico bastante joven llamado Sigmund Freud (1856-1939) iba reuniendo experiencias clínicas que lo llevarían a sentar las bases de una doctrina, el psicoanálisis (Roudinesco 2015). También en esos años un psicólogo asimismo muy joven, Lightner Witmer (1867-1956), inauguraba la Psychological Clinic en la University of Pennsylvania en 1896, sentando así las bases de la psicología clínica (McReynolds 1987). 
Hay demasiadas teorías que no solo compiten entre sí, sino que reclaman (cada una) la condición de ser las únicas que están en posesión de la verdad en materia de la res psychologica; hay demasiados términos que tienen significados diferentes según un autor o de acuerdo con otro; hay desafíos provenientes de la etología, de la sociobiología y, más recientemente, de las neurociencias, que proponen explicaciones y puntos de vista que relativizan o, en determinados aspectos, hasta cuestionan de raíz lo que la psicología propone.

\section{Los múltiples significados de un término}

Para comenzar, el sustantivo Psicología es problemático, casi engañoso, pues ha tenido varios significados desde que fue incorporado al lenguaje común, y aún hoy es entendido de modo diverso, según el enfoque teórico que se asumai".

La historia de las palabras refleja la historia de cada grupo humano que las crea y que le da diferentes significados y hasta usos según sus necesidades y vicisitudes. Esto también rige para la psicología. Vidal (2006) ha estudiado la evolución del término psicología desde el siglo XVIII hasta nuestros días: hoy es definida como la ciencia de la conducta; a finales del siglo XVI y comienzos del XVII ya se empleaba la palabra psicología, pero con otro sentido, entendiéndosela como una suerte de física del alma, nutrida de la filosofía natural y de la antropología cristiana.

\section{Cuatro niveles de conocimiento psicológico}

Las cosas han cambiado hoy. Pero no mucho: aunque en la actualidad los psicólogos comparten en líneas generales una definición uniforme de la psicología, podemos observar también que el término Psicología hace referencia, en realidad, a diferentes niveles de comprensión de la conducta del ser humano, niveles a los que denominaremos Psi I, Psi II, Psi III, y Psi IV.

Psi I es el conocimiento psicológico popular, propiedad de todos y alimentado de lo que podríamos llamar la sabiduría acumulada por un grupo social en el devenir de su historia; algo así como la psychologia perennis. Se trata de un conocimiento inestructurado, asistemático, que se basa en vivencias y suposiciones compartidas por un grupo humano acerca de la naturaleza y la condición humanas.

\footnotetext{
i Se suele afirmar que la palabra psicología fue empleada por primera vez en un tratado (hoy lamentablemente perdido) escrito por Marcus Marulus (o Marko Marulic, 1450-1524), un humanista dálmata (Brozek 1973, Massimi 1983) pero hay algunas dudas sobre el particular. Rodolphus Goclenius, en latín, o Rudolf Gockel en alemán (1547-1628) fue uno de los primeros en emplear la palabra psicología (Goclenius 1590). Obviamente, en la pluma de Marcus Marulus o en la de Goclenius, psicología tenía un significado diferente (muy diferente) al que ha tenido cuando la empleaban John B. Watson o Lev S. Vygotsky.
} 
Mucho de ese saber psicológico se encuentra expresado -explícita o implícitamenteen refranes y en sentencias ("más vale lo malo conocido que lo bueno por conocer", "dime con quién andas y te diré quién eres", "a quien madruga Dios lo ayuda")ii".

Este es el tipo de conocimiento psicológico de "uso" diario, por medio del cual las personas sin mayor formación psicológica suelen guiar su conducta en relación con otras personas. También se conoce a este tipo de conocimiento psicológico como naif psychology.

Los psicólogos académicos suelen mirar con cierta condescendencia este saber, pero no debemos olvidar que el conocimiento psicológico popular, como su nombre lo dice, es el que predomina entre la gran mayoría de personasiv.

Por Psi II designamos al conocimiento psicológico contenidas en obras literarias y artísticas en general. ¿Qué duda cabe que Otelo, de William Shakespeare (I5541616), es la mejor presentación de los celos, o que Abel Sánchez, de Miguel de Unamuno (I864-1936), nos propone de modo claro y cautivador la fuerza, la influencia y las consecuencias de la envidia?v: muchos psicólogos y psiquiatras han reconocido la deuda que tiene la psicología con la literatura y suelen recomendar a los estudiantes que se acerquen a las obras literarias a fin de enriquecer sus puntos de vista y conocimientos con el saber psicológico que se encuentra en ellas ${ }^{\mathrm{vi}}$.

Honorio Delgado (1892-1969), importante psiquiatra y psicólogo peruano, consideraba

“...valiosas las descripciones de los grandes literatos que sufren y estudian sus flaquezas y anormalidades: Dostoievski, Amiel, Rousseau. Grillparzer, Hebbel, Cellini, Leopardi, De Quincey, Baudelaire, Maupassant, Proust y tantos otros" (Delgado, 1969; pg. 29).

Psi III es el conocimiento psicológico un poco más elaborado que proviene de la experiencia prolongada de personas que por sus actividades tienen un acceso privilegiado a ciertas situaciones y singularidades de la condición humana: el psicoterapeuta, en cuyos archivos reposan las historias clínicas y sus apuntes de 100-200 consultantes acumulados en el lapso de 10-15 años de experiencia; el

\footnotetext{
iii Un antropólogo, Paul Radin (1883-1959), escribió una obra titulada El hombre primitivo como filósofo (Radin 1973), en la que resume sus hallazgos en materia de refranes, leyendas, mitos en sus investigaciones en grupos humanos en el África subsahariana.

iv Podríamos decir, en ese sentido, que cada sociedad tiene su psicología. Las experiencias frecuentes en una colectividad determinada van sedimentando juicios y percepciones que son aceptados casi de manera automática por sus integrantes y, por tanto, guían su comportamiento.

v Podríamos agregar a Dostoievski y Tolstoi, con obras como Crimen y castigo y Ana Karenina.

vi Sobre Shakespeare y su influencia e importancia para el mundo de la psicología es altamente recomendable la lectura de Bloom (2008).
} 
sacerdote que ha "escuchado" cientos de confesiones y atendido innumerables solicitudes de orientación espiritual; el abogado penalista de amplia experiencia, que ha representado cientos de casos de homicidio, de violación o de incesto.

Este tipo de conocimiento es el que "circula" entre psicoterapeutas, abogados que discuten un caso, sacerdotes que reflexionan sobre problemas espirituales, trabajadoras sociales que organizan alguna acción de ayuda a niños abandonados o a reclusos en proceso de reeducación.

Ilustra este tipo de psicología la obra escrita de Irvin Yalom ( 93 |-), psicoterapeuta norteamericano poseedor de una excelente y prolífica pluma, que ha dado a la luz aparte de importantes trabajos en los que trata de su trabajo terapéutico (por ejemplo Yalom 2000)- numerosas novelas en las que vierte su experiencia y reflexiona sobre la naturaleza humana a partir de su trato con clientes y consultantes (mencionemos a guisa de ilustración El enigma Spinoza, Yalom 2012, y El día que Nietzsche lloró, Yalom 1995).

Y, por último, Psi IV es el saber psicológico tal como se entiende en las universidades y tal como se enseña a quienes quieren convertirse en psicólogos profesionales.

Se trata de un saber establecido desde el último cuarto del siglo XIX, acumulativo, y plasmado en tratados de psicología generalvii o de áreas específicas de la psicología. Ese saber se define a sí mismo como científico, favoreciéndose por tanto del prestigio que posee la ciencia en el mundo occidental.

Es un saber basado en experiencias sistemáticas y sistematizadas, repetidas en varias partes del mundo y en diferentes momentos; es un saber aprendible por medio de una instrucción organizada en cursos, años académicos y acreditado por medio de certificados, diplomas, grados y títulos.

En la siguiente tabla se presentan algunas de las características más destacadas de estos cuatro niveles del saber psicológico.

vii Nos referimos a manuales de amplia circulación en el pasado, como los de James O. Whittaker (Whittaker 1968), Enrique Cerdá (Cerdá 1965), Agostino Gemelli y Giogio Zunini (Gemelli \& Zunini 1964), hoy en los depósitos de muchas bibliotecas universitarias, pues han sido remplazados por los modernos textos de Linda Davidoff (Davidoff 1989) o Diane E. Papalia \& Sally B. Olds (Papalia \& Olds 2000).

En el Perú tendríamos que mencionar tres manuales de acuerdo con un orden cronológico: Psicología (Delgado \& Iberico 1933), Introducción a la psicología experimental (Blumenfeld 1946), y Lecciones de psicología general (Russo Delgado 1962), hoy apenas consultados pero que aun no han encontrado remplazos provenientes de la pluma de psicólogos peruanos contemporáneos. 
Tabla I: Características de los cuatro niveles propuestos del saber psicológico

\begin{tabular}{|c|c|c|c|c|}
\hline Aspecto & PSI I & PSI II & PSI III & PSI IV \\
\hline Naturaleza & $\begin{array}{l}\text { Espontáneo, } \\
\text { asistemático, } \\
\text { basado en la } \\
\text { experiencia de las } \\
\text { personas y de los } \\
\text { pueblos }\end{array}$ & $\begin{array}{l}\text { Puede entenderse } \\
\text { como un estudio } \\
\text { de caso }\end{array}$ & $\begin{array}{l}\text { Surgido en la } \\
\text { experiencia de } \\
\text { quienes se ven } \\
\text { confrontados con } \\
\text { problemas humanos } \\
\text { excepcionales } \\
\text { (crím e n e s, } \\
\text { violaciones, } \\
\text { terrorismo) }\end{array}$ & $\begin{array}{l}\text { Sistematizado } \\
\text { y basado } \\
\text { en estudios } \\
\text { conducidos } \\
\text { con el uso de } \\
\text { experimentos, } \\
\text { tests, inventarios, } \\
\text { en trabajos de } \\
\text { investigación }\end{array}$ \\
\hline Método & $\begin{array}{l}\text { Observación } \\
\text { incidental, } \\
\text { a cumulación } \\
\text { de experiencias } \\
\text { cotidianas }\end{array}$ & $\begin{array}{l}\text { Análisis literario de } \\
\text { alguna emoción } \\
\text { o estado de la } \\
\text { conducta }\end{array}$ & $\begin{array}{l}\text { Observación más } \\
\text { reflexión }\end{array}$ & $\begin{array}{l}\text { Observación } \\
\text { más reflexión } \\
\text { más verificación } \\
\text { víar estudios } \\
\text { específicos }\end{array}$ \\
\hline Validez & $\begin{array}{l}\text { Se la considera de } \\
\text { validez general, al } \\
\text { menos para cada } \\
\text { grupo social }\end{array}$ & $\begin{array}{lr}\text { Se la puede } \\
\text { entender } & \text { como } \\
\text { una } & \text { valiosa } \\
\text { descripción de la } \\
\text { conducta }\end{array}$ & $\begin{array}{l}\text { Se la considera } \\
\text { con validez para las } \\
\text { situaciones humanas } \\
\text { a las que se refiere } \\
\text { y se fundamenta en } \\
\text { la experiencia de } \\
\text { quienes trabajaron } \\
\text { con personas en } \\
\text { situaciones difíciles }\end{array}$ & $\begin{array}{l}\text { Se la considera de } \\
\text { validez universal, } \\
\text { aunque en los } \\
\text { últimos años se } \\
\text { señala que solo } \\
\text { posee validez } \\
\text { en una sociedad } \\
\text { y en un tiempo } \\
\text { determinados }\end{array}$ \\
\hline Verificación & $\begin{array}{l}\text { Por lo general } \\
\text { no se la verifica, } \\
\text { sino solo se la } \\
\text { confirma de caso }\end{array}$ & $\begin{array}{l}\text { Se la da por } \\
\text { adecuada }\end{array}$ & $\begin{array}{l}\text { La palabra del } \\
\text { experto en el tema } \\
\text { basta }\end{array}$ & $\begin{array}{l}\text { Replicación de } \\
\text { estudios }\end{array}$ \\
\hline
\end{tabular}

Psi I y Psi II no han experimentado mayores cambios en el curso de la historia. En el caso de Psi III, libros en los cuales abogados, terapeutas y sacerdotes dan a conocer sus experiencias o presentan sus memorias, han contribuido a que éste se acreciente.

En Psi ll no solo literatos, también músicos y pintores deberían ser incluidos en la lista de importantes estimuladores del saber psicológico con sus obras. Composiciones como las de Beethoven (La Quinta Sinfonía) o Rachmaninoff (El concierto para piano número 2) o cuadros como los de Rene Magritte (1898-1967) o Giorgio de Chirico ( 1888 - 1978 pueden ser mencionados como ilustración de lo que estamos afirmando. El grito, de Edvard Munch (I 863-1944), es un contundente ejemplo, en su extraordinaria sencillez, de la riqueza de contenido psicológico que puede tener una obra pictórica. Volveremos a esto más adelante. 
El Psi IV, el de la así llamada psicología cientíica, es aquel en el cual se puede observar avances, desarrollos y revoluciones. Se trata de un saber acumulativo, que se origina en un buen número de casos en el laboratorio, y en otros, no menos numerosos, a través de estudios psicométricos en los que se emplean tests o cuestionarios.

En este nivel, los psicólogos aspiran a formular leyes que expliquen el comportamiento humano y, consecuentemente, permitan a corto o largo plazo controlarlo y regularlo. Asimismo, en este nivel los psicólogos emplean un lenguaje técnico por lo general no accesible a quien carece de formación psicológica. Hay además una creciente matematización de este saber.

Resulta claro que mientras Psi l y Psi ll reclaman validez en base a lo que le ocurre a la gente cada día o remitiéndose a la autoridad de un Shakespeare o de un Aristóteles, Psi IV la reclama por el hecho de que se le puede constatar y verificar en el tiempo y en diferentes lugares por medio de la replicación de estudios.

\section{La psicología científica como fenómeno social}

La psicología cientíica es un fenómeno social, es decir no es el resultado de la casualidad ni de la acción de un solo hombre. Cuando se lee que el padre de la psicología experimental o psicología científica es Wilhelm Wundt puede surgir la idea de que la psicología surgió gracias a la voluntad de hierro y a la perseverancia de este científico.

En realidad tal afirmación es solo un simple recurso didáctico. Ninguna ciencia tiene padre ni madre. Como fenómeno social, toda ciencia responde a las necesidades y demandas de un grupo humano organizado, cuyas expectativas varían en el transcurso del tiempo y al hacerlo determinan el rumbo que cada ciencia toma y el perfil que la distingue en cada época.

Esto vale para todos los casos, pero de modo especial para las ciencias que tienen como su objeto la conducta del ser humano.

La psicología como ciencia surge en el siglo XIX en Europa Central; no podría haber surgido en la Europa o el África del siglo XI o del XIII. La psicología científica surge en el siglo XIX y en Europa en el marco social de un siglo en el cual se producen grandes cambios, que solo mencionaremos de manera muy esquemática:

(a) La Revolución Francesa, que cancela toda una forma de pensar, de gobernar y de ser desde tiempos inmemoriales, destacando el valor de los individuos y el derecho que ellos tienen a la libertad y a la condición de iguales. 
Dejando de lado a personajes como Robespierre, Marat y Danton, de gran significado en el plano de la políica, encontramos en los años previos a la Revolución Francesa a pensadores decisivos en la comprensión de los seres humanos, como Jean Jacques Rousseau (I7/2-1778) viii, el autor de El contrato social y el Emilio, o de proyectos que intentan ofrecer una imagen del ser humano no más dentro de los parámetros de la religión, sino desde una perspectiva que se adelanta a lo que hoy es lo usual. Nos referimos a esa gran empresa editorial que es La Enciclopedia (Blom 2007, 20 I0).

A pesar de los excesos cometidos durante la época del Gran Terror y de las temibles acciones de Robespierre y de los proyectos totalitarios de Saint-Just, la Revolución Francesa fue saludada en su época por muchos de los representantes de la llustración, como Inmanuel Kant (véase por ejemplo Die Streit der Fakultäten, el último libro que diera a la imprenta Kant en 1798; Kant 2003) (Bilbeny 1989) ${ }^{i x}$, quienes reconocieron con toda claridad su significado para el conocimiento y la valoración de los seres humanos y de las relaciones entre ellos. Debe anotarse, sin embargo que hubo un grupo que tomó decidida distancia de lo que ocurría en Francia ${ }^{x}$.

(b) La Revolución Industrial, cuyas consecuencias humanas (emigración masiva del campo a la ciudad, hacinamiento en los grandes centros industriales, la explotación asociada al trabajo) han sido magistralmente retratadas en la novela de Charles Dickens (1812-1870) Tiempos dificiles (Dickens 1972), pero que también dio lugar al progreso social que, a su vez, trajo consigo exigencias en cuanto a rendimiento, a habilidades y capacidades por parte de los trabajadores.

Winkler (2009) escribe sobre el particular lo siguiente:

"La época de la industrialización fue un tiempo de miseria colectiva y de inescrupulosa explotación laboral de los seres humanos: tan terrible como Friedrich Engels la describió en 1945 en su trabajo "La situación de la clase trabajadora en Inglaterra. Sin el extendido trabajo infantil en las minas y en fábricas, innumerables familias de trabajadores no hubieran podido sobrellevar

viii Rousseau es uno de los personajes más interesantes del siglo XVIII, que aún hoy día ejerce un poder seductor en muchos pensadores y estudiosos, como lo demuestra la gran cantidad de biografías que aún hoy siguen apareciendo sobre él (León 2013). Podemos decir que casi no hay escrito suyo o algún capítulo de su vida que no haya sido objeto de detenido escrutinio hasta el día de hoy. Citemos solo a modo de ilustración los trabajos dedicados a él y a su pensamiento escritos por Cassirer (2007), Starobinski (1983). Ni Montesquieu ni Voltaire, los otros dos grandes precursores ideológicos de la Revolución Francesa, despiertan tanta curiosidad como Rousseau. Brinkmann (2011) cree encontrar en Rousseau a un lejano precursor de esa importante corriente contemporánea que es la psicología humanística

ix Bilbeny señala que

“...Kant, hasta su muerte, en 1804, nunca abjuró de su compromiso con el hecho de la Revolución y los principios que la inspiraron. Ve en ellos la promesa de realización de los derechos de la razón práctica en un sistema legal, o lo que venía a ser lo mismo: la oportunidad de una puesta en práctica de la nueva filosofía política encabezada por su admirado Rousseau" (pg. 23).

Sin embargo, su postura no es nada favorable cuando se trata de la rebelión contra el régimen monárquico:

"Kant simpatiza con los principios conducentes a 1789 pero al mismo tiempo desautoriza el derecho a la rebelión civil" (pg. 25). 
su miserable existencia. Pero la miseria hubiera sido mucho mayor si no se hubiera dado la posibilidad del trabajo industrial. La industrialización llevó no a un empobrecimiento mayor sino a un avance social del proletariado. El ingreso real de las familias trabajadoras mostró en todas las sociedades industriales de Occidente una tendencia a la alza durante largo tiempo. A ello contribuyó la actividad de los sindicatos. Las predicciones en 1789 del economista inglés Thomas Robert Malthus de que el crecimiento de los medios de alimentación permanecería por debajo del crecimiento de la población no se cumplió como tampoco el pronóstico formulado seis décadas después por Karl Marx de que los sueldos de los trabajadores caerían con el paso del desarrollo capitalista por debajo del mínimo de la existencia" (pg. 259)

(c) El avance experimentado en otras disciplinas que comienzan a ganar el perfil que hoy día las distingue como saber científico: el conocimiento sobre el sistema nervioso experimenta un avance decisivo en el siglo XIX gracias a Pierre Flourens y Broca; la fisiología se beneficia de las ideas de Charles Bernard y del establecimiento de los primeros laboratorios en el sentido moderno del término; la estadística, central en el moderno conocimiento psicológico, se enriquece con las ideas de Adolphe Quetelet (1796- | 874) y de Carl Friedrich Gauss ( 1777- 1855).

Algo que merece ser destacado es que con el paso del tiempo la reflexión acerca del ser humano, de su naturaleza, de su comportamiento y sus características va alejándose del ámbito de la teología (como había sido el caso en la época de San Agustín y Santo Tomás) y de la filosofía (Pascal, por ejemplo) para ser influido y determinado por aportes provenientes de las ciencias naturales (entre ellas, la fisiología). Esto trae consigo el progresivo retroceso del alma como la protagonista principal de la vida psicológica.

\section{Corrientes filosóficas que influyeron en el surgimiento de la psicología científica}

Está también la presencia de cinco corrientes filosóficas y científicas que influyen en la atmósfera en la cual se desarrolla la psicología científica. Ellas son:

(a) El positivismo, corriente filosófica surgida gracias a la acción incansable y casi mesiánica de Auguste Comte, uno de los personajes más originales de la escena científica francesa del siglo XIX;

(b) El empirismo, cuyos planteamientos pueden encontrarse ya en John Locke ( | 632-1704), y que destaca la importancia de la experiencia como forma de conocimiento; 
(c) El materialismo, en cuyos orígenes podemos encontrar el nombre de Demócrito, y que plantea la existencia de una base material en todos los fenómenos de la realidad;

(d) El evolucionismo, con los nombres de Charles Darwin (|809-1882) y Ernst Haeckel ( 834 - 1919), que destaca la idea del desarrollo; y, por último,

(e) El romanticismo, que insiste en la importancia de la vida subjetiva.

Estas corrientes influyen de consuno en la forja de una atmósfera intelectual ajena al pensamiento religioso, refractaria a explicaciones metafísicas y orientada más bien a la búsqueda de hechos y evidencias concretas, si bien admite, debido al romanticismo, la realidad subjetiva propia de cada ser humano.

La psicología como ciencia encuentra en esa atmósfera un excelente caldo de cultivo recibiendo un poderoso estímulo en la cada vez más respetada y difundida fisiología. No olvidemos que Wundt publicó algunos años antes de fundar el laboratorio de Leipzig, su Grundzüge der physiologischen Psychologie (Wundt 1874).

La siguiente tabla presenta de manera esquemática la influencia de cada una de estas corrientes de la psicología:

Tabla 2: Las corrientes que influyeron en el surgimiento de la psicología científica

\begin{tabular}{|c|c|c|c|}
\hline Corriente & Representantes & Idea central & Influencia en la psicología \\
\hline Positivismo & Auguste Comte & $\begin{array}{l}\text { Solo lo empírico } \\
\text { es lo valedero } \\
\text { para la ciencia }\end{array}$ & $\begin{array}{l}\text { Proponerla como ciencia, } \\
\text { descartando conceptos como } \\
\text { alma y espíritu }\end{array}$ \\
\hline Empirismo & John Locke & $\begin{array}{l}\text { La experiencia } \\
\text { es la fuente de } \\
\text { conocimiento }\end{array}$ & $\begin{array}{l}\text { Enfasis en el experimento y en la } \\
\text { sensación y en la percepción }\end{array}$ \\
\hline Materialismo & Demócrito & $\begin{array}{l}\text { Todo tiene una } \\
\text { base material }\end{array}$ & Estudio del sistema nervioso \\
\hline Evolucionismo & Charles Darwin & $\begin{array}{l}\text { La idea de } \\
\text { desarrollo }\end{array}$ & $\begin{array}{l}\text { Insistencia en los procesos } \\
\text { evolutivos }\end{array}$ \\
\hline Romanticismo & $\begin{array}{l}\text { Varios, por ejemplo } \\
\text { Johan Wolfgang von } \\
\text { Goethe }\end{array}$ & $\begin{array}{l}\text { La importancia de } \\
\text { la subjetividad }\end{array}$ & $\begin{array}{l}\text { Estudio de las emociones y } \\
\text { diversos estados afectivos }\end{array}$ \\
\hline
\end{tabular}

\footnotetext{
xi Sobre el particular vale la pena citar un párrafo de la obra de Jarochewski titulada Psychologie im 20. Jahrhundert (1975):

"La realidad psicológica fue descubierta por científicos naturales, biólogos, fisiólogos, físicos y médicos. Pero ellos no se consideraban a sí mismos ni fueron considerados por otros como investigadores profesionales de ella. Como tales se solía ver en esa época a los filósofos, cuyo más antiguo dominio de actividad era el análisis del espíritu y sus funciones. Después de que se descubrió la posibilidad de que esas funciones pudieran ser exploradas con los métodos propios de las ciencias naturales, a través de experimentos, métodos clínicos, con la ayuda de las matemáticas y de la estadística, se inició el proceso de emancipación de la psicología" (p. 110).
} 
Es un hecho que las relaciones entre la psicología y la filosofía continúan siendo muy estrechas, a despecho del esfuerzo de muchos psicólogos por demostrar lo contrario. Penna ha escrito un interesante libro que explora sus relaciones (Penna 2006).

Pero, desde su surgimiento, la psicología se ha desarrollado bajo la influencia de cambios sociales dramáticos y de la lógica inmanente de su propia evolución. Cada gran conmoción o desarrollo social ha hecho sentir sus consecuencias en la psicología.

Las dos guerras mundiales constituyeron sangrientas ocasiones para que los psicólogos demostraran la utilidad de su saber en la empresa bélica.

El nacionalsocialismo, el fascismo y el comunismo, estimularon la reflexión y los estudios en el terreno de la psicología social, tratando temas como el de la personalidad autoritaria (Adorno et al. 1965), la forma en que las personas asumen decisiones políticas (Eysenck 1964); y, recientemente, el terrorismo ha motivado estudios innumerables que tratan de entender su naturaleza y los rasgos psicológicos de quienes los practican (Merari 20 I 0). La globalización, por otro lado, ha relativizado mucho del saber psicológico considerado como de validez universal, promoviendo los estudios transculturales. Por último, el impacto de las neurociencias estimula la investigación psicofisiológica de manera constante.

\section{La psicología como ciencia de la conducta}

Se dice que la psicología es la ciencia de la conducta. Es cierto, pero asimismo es verdad que otras ciencias no menos importantes también analizan la conducta. El derecho estudia la conducta desde el eje de lo lícito y el delito; la sociología estudia la conducta de la persona en las diversas estructuras sociales; la antropología, los usos y costumbres que cada conducta comprende; la lingüística la conducta verbal; la economía, la conducta desde el ángulo de la producción y el consumo. La psicología se diferencia de todas ellas en el hecho de que estudia la conducta y la subjetividad de los seres humanos.

En los últimos veinticinco años del siglo $X X$ se popularizó en las comunidades académicas norteamericanas el término behavioral sciences, que no solo se refería a la psicología sino también a las otras ciencias antes mencionadas (economía, derecho, antropología, sociología, lingüística, pero también la politología, la psiquiatría y hasta la neuropsicología).

Es obvio que la psicología no basta para explicar por sí sola la conducta humana y todas sus variedades. En su ayuda deben concurrir también la antropología y la 
sociología. Pero, asimismo, las ciencias naturales (en los últimos años, la genética y, cada vez con más fuerza, las neurociencias).

De hecho, para los psicólogos el conocimiento antropológico constituye una de las fuentes de mayor enriquecimiento/cuestionamiento de su saber. Si quisiéramos presentar las ideas en términos muy simples, diríamos que el antropólogo es quien le dice al psicólogo si lo que ve y observa en cada cultura es normal o anormal. Ampliamos esto en la siguiente sección.

\section{La psicología y las ciencias sociales}

Los psicólogos no suelen saber mucho de antropología y de sociología, pero muchos antropólogos y sociólogos sí poseen un adecuado conocimiento de la psicología.

¿Qué puede ganar un psicólogo cuando se acerca a la antropología y la psicología? Mencionemos solo dos ejemplos.

Cuando un psicólogo se acerca a otra cultura y observa los comportamientos predominantes en ella, es muy probable que experimente la tentación de calificarlas como normales o anormales a partir de su propio contexto cultural. Sin embargo, sería bueno que consultara con un antropólogo, pues él será quién le dirá si la conducta $X \circ Z$ es normal o anormal en la cultura que el psicólogo está observando y que no es la suya. Y los sociólogos podrán ofrecerle el marco interpretativo para entender variedades de comportamiento a partir de variables como género, grupo étnico, nivel socioeconómico.

Sociólogos y antropólogos han enriquecido y diferenciado el conocimiento psicológico. Debemos a Émile Durkheim (|858-1917) un penetrante estudio sobre el suicidio (Durkheim 2008), un clásico de la sociología pero también de la psicología, que aun sigue siendo reeditado y leído. Debemos a Max Weber (I864-1920) un análisis polémico pero muy sugerente del papel de la religión en el desarrollo del capitalismo. Y antropólogos como Margaret Mead (1901-1978), Ruth Benedict (I887-1948) y Bronislaw Malinowski (I884-1942) han analizado con menor o mayor provecho la universalidad de la teoría psicoanalítica.

Otras ciencias sociales no son menos importantes para los psicólogos. Consideremos solo una, tal vez la más prestigiada de todas ellas: la economía.

Ninguna sociedad organizada puede existir sin la presencia de dos procesos centrales para la economía: la producción y el consumo. Al estudio de ambos desde la psicología se han dedicado numerosos estudios, hoy día con mayor frecuencia dada la insistencia en la competitividad y la complejidad de la sociedad capitalista. 


\section{La psicología y las artes}

El novelista Milan Kundera señaló que la literatura descubrió al inconsciente antes que el psicoanálisis y la psicología (Kundera 1999). Ciertamente, no es el único que señala la importancia de la creación literaria para el conocimiento de la naturaleza humana. Nada menos que el padre del psicoanálisis, Sigmund Freud, reconoció la importancia de la obra de uno de los grandes escritores de la Viena de fines del siglo XIX y comienzos del siglo XX, Arthur Schnitzler (|862-193|), quien a su vez fue notoriamente influido por Freud ${ }^{\mathrm{xii}}$.

La siguiente tabla presenta diez obras literarias que por su contenido constituyen importantes y sugerentes lecturas para los psicólogos y estudiantes de psicología.

\section{Tabla 3: Diez obras literarias de interés para los psicólogos}

\begin{tabular}{|c|c|c|c|}
\hline Nro. & Obra & Autor & Temas psicológicos \\
\hline 01 & Hamlet & Shakespeare & La duda, la indecisión patológica \\
\hline 02 & Otelo & Shakespeare & Los celos \\
\hline 03 & Crimen y castigo & Dostoievski & $\begin{array}{l}\text { Conducta criminal, culpa, } \\
\text { remordimiento }\end{array}$ \\
\hline 04 & Edipo rey & Sófocles & Incesto \\
\hline 05 & Don Quijote & Cervantes & Introversión, locura \\
\hline 06 & La metamorfosis & Franz Kafka & Alteraciones en la imagen corporal \\
\hline 07 & La montaña mágica & Thomas Mann & $\begin{array}{l}\text { Temas de la psicología de la salud y de } \\
\text { la enfermedad }\end{array}$ \\
\hline 08 & Abel Sánchez & Miguel de Unamuno & Envidia \\
\hline 09 & Hambre & Knut Hamsun & Efectos psicológicos del hambre \\
\hline 10 & $\begin{array}{l}\text { El cuaderno dorado } \\
\text { de notas }\end{array}$ & Doris Lessing & $\begin{array}{l}\text { Problemática psicológica y sociológica } \\
\text { de la mujer en el siglo XX }\end{array}$ \\
\hline
\end{tabular}

xii Estudiando las obras de Freud y de Schnitzler, Berry (2012) señala que

"El primero fundó el psicoanálisis, que puso de cabeza a la psiquiatría contemporánea y ha dejado una huella indeleble en el pensamiento occidental. El segundo exploró la sexualidad humana y la psique en sus textos literarios, e introdujo el monólogo interno o la técnica narrativa de "la corriente de conciencia en la literatura alemana. Mientras que los trabajos de Freud tienen un gran reconocimiento, los de Schnitzler se mantienen vivos a través de producciones teatrales y adaptaciones fílmicas (tales como La Ronde, 1950, de Reigen, y Eyes wide shut, de Stanley Kubrick, 1999, de Traumnovelle). Las conexiones entre ambos pioneros en la investigación del psiquismo son muchas: el método de asociación libre empleado por Freud en Estudios sobre la histeria (1895) muestra una notoria similaridad de comprensión de la conciencia humana con la narrativa de corriente de la conciencia empleado por Schnitzler en el Teniente Guestl (1900) y la Señorita Elsa (1924). La interpretación de los sueños (1900), que Freud consideraba su más importante obra, ha demostrado ser una herramienta muy valiosa para interpretar los sueños que aparecen en las obras de Schnitzler, , aun en aquellos escritos antes de la aparición de la obra de Freud" (pp. 5-6). 
Solo hemos citado diez libros; ciertamente podríamos haber citado muchos más. Están allí las obras de Herman Melville (Moby Dick, Bartleby), Heinrich Mann (El ángel azul), Alberto Moravia (El desprecio), Luigi Pirandello (Seis personajes en busca de un autor), Albert Camus (El extranjero), para solo mencionar algunos autores.

Las grandes obras literarias presentan de manera paradigmática una situación humana concreta. Podemos decir que se trata de verdaderos estudios de caso, en los que situaciones como el adulterio (Ana Karenina, de Leon Tolstoi), el absurdo (El proceso, de Kafka), la hipocondría (El enfermo imaginario, de Moliere), entre otras, son descritas y expuestas magistralmente.

En algunos casos la literatura ha explorado en detalle situaciones existenciales a las que la psicología se ha acercado tiempo después y con las limitaciones propias de su metodología. La realidad de la muerte ha sido tratada en detalle por Hermann Broch en Muerte de Virgilio; la atracción homosexual fue el centro de la obra Muerte en Venecia, de Thomas Mann.

Una breve mención debe hacerse a un género literario por lo general mirado con cierta displicencia: la novela de misterio y policiaca. Para muchos autores, la novela de misterio y policiaca es por definición una novela psicológica, independientemente de la calidad que ella posea.

El personaje de Sherlock Holmes, que creara Arthur Conan Doyle, es digno de un estudio psicológico (véase por ejemplo Fleischhack 20 I 5), como también lo son los diversos personajes a los que diera vida la escritora norteamericana Patricia Highsmith (el más conocido de los cuales es Tom Ripley, pero también Edith, la protagonista de El diario de Edith).

El teatro también ha hecho lo suyo: desde Edipo Rey de Sofocles, hasta ¿Quién le teme a Virginia Woolf?, pasando por Viaje al fin de la noche, de Eugene $O$ 'Neill, y Las brujas de Salem, de Arthur Miller (véase Oyebode 2009, 20I2).

Agreguemos otra tabla, en la cual enumeramos diez creaciones artísticas (esculturas, pinturas, composiciones musicales) que, solo a modo de ejemplo, tienen también un contenido psicológico que puede ser explorado por quien se acerque a ellas. 


\section{Tabla 4: Diez obras artísticas de interés para los psicólogos}

\begin{tabular}{|c|c|c|c|c|}
\hline Nro. & Obra & Autor & Naturaleza & Temas psicológicos \\
\hline 01. & La piedad & Miguel Angel & Escultura & El sufrimiento \\
\hline 02. & El grito & Edvard Munch & Pintura & La desesperación \\
\hline 03. & $\begin{array}{l}\text { Concierto para } \\
\text { piano nro. } 2\end{array}$ & $\begin{array}{l}S \text { e } r \text { g e i } \\
\text { Rachmaninoff }\end{array}$ & Música & Melancolía, depresión \\
\hline 04. & Melancolia I & Alberto Durero & Pintura & Melancolía, depresión \\
\hline 05. & La madre & Henry Moore & Escultura & $\begin{array}{l}\text { Imágenes de la figura } \\
\text { materna }\end{array}$ \\
\hline 06. & El pensador & Auguste Rodin & Escultura & Concentración, tristeza \\
\hline 07. & $\begin{array}{l}\text { Catedral "La } \\
\text { Sagrada Familia" } \\
\text { (Barcelona) }\end{array}$ & Antonio Gaudí & Arquitectura & $\begin{array}{l}\text { Expresiones de la creatividad } \\
\text { asociada a la religión }\end{array}$ \\
\hline 08. & Diversas pinturas & Salvador Dalí & Pintura & $\begin{array}{l}\text { Expresiones del } \\
\text { inconsciente }\end{array}$ \\
\hline 09. & $\begin{array}{lr}\text { Sinfonía } & \text { nro. } \\
5 \quad \text { (Sinfonía } & \text { del } \\
\text { Destino) } & - \\
\text { Sinfonía nro. } & 9 \\
\text { (Coral) } & \end{array}$ & $\begin{array}{l}\text { Ludwig van } \\
\text { Beethoven }\end{array}$ & Música & $\begin{array}{l}\text { Diferentes estados afectivos } \\
\text { (éxtasis, desesperación, } \\
\text { entusiasmo, melancolía) }\end{array}$ \\
\hline 10 & Moisés & Miguel Angel & Escultura & Decisión, liderazgo \\
\hline
\end{tabular}

Es relativamente fácil entender que la literatura influya sobre la psicología y viceversa, es un poco más complicado reconocer la influencia de otras artes en el saber psicológico. Sin embargo, la relación de obras de arte señaladas en la tabla anterior permite reconocer esa influencia. Las dos esculturas de Miguel Ángel presentan de modo claro estados emocionales intensos, como son el sufrimiento y el liderazgo y han servido de inspiración a Freud en el caso del Moises para estudios psicológicos. Algo semejante puede decir de la obra de Munch y de Melancolia I de Durero. Por último, encontramos en la arquitectura obras como la de Gaudi y el Castillo de Neuschwanstein que bien merecen no solo un análisis propio de sus especialidades sino que dan lugar a reflexiones de naturaleza psicológica.

\section{La psicología, la genética y las neurociencias}

Desde siempre ha habido en la psicología una encendida polémica acerca de qué es lo que tiene un rol más importante en la conducta: si el ambiente o si los elementos genéticos. En cada una de las posiciones podemos encontrar a figuras muy importantes e influyentes en la psicología. Para solo mencionar dos nombres: 
Jean Piaget, destacando los aspectos genéticos, y Lev S. Vygotsky, haciendo lo mismo con los ambientales y culturales.

En los últimos, el desarrollo de las neurociencias y su avance vertiginoso ha hecho que la posición genetista vuelva a cobrar gran importancia. Autores como Michael Gazzaniga (1939-), por ejemplo, o, aun más conocido, Antonio Damasio (1944-), han dado particular fuerza explicativa a la perspectiva neurocientista.

El entusiasmo que han provocado las neurociencias desborda los límites de la psicología y se expresa en la inmensa cantidad de publicaciones provenientes de quienes trabajan en ellaxiii. Por eso encontramos hoy neuroética, neuroteología, neuroeconomía, etc. No faltan voces críticas, como la de Tallis (20l I), que hablan de una neuromanía, una suerte de moda como muchas otras que ha experimentado la psicología en el pasado (véase también Legrenzi \& Umiltà (20 I l).

En todo caso, es un hecho incontestable que la psicología no puede desarrollarse ni proponer enfoques serios de la conducta humana si no toma en cuenta los aportes de las ciencias biológicas, y, en particular de las neurociencias. Con ello parece cumplirse el dictum de Johannes Müller, Nemo psychologus nisi physiologus [no se puede ser psicólogo si no se es fisólogo] (Meulders 20 I0).

Esto, sin embargo, no es ninguna novedad. Por el contrario, es algo que siempre ha ocurrido en la psicología, como lo señalan Stockhorst et al. (201 I) al indicar que en la monumental obra de Wundt, Grundzüge der physiologischen Psychologie (Wundt 1874), se sientan las bases de la psicología general y biológica.

Debe anotarse, sin embargo, que en la formación universitaria de los psicólogos, si exceptuamos los cursos de estadística y de neuroanatomía, hay grandes carencias en lo tocante a matemáticas, informática y fisiología.

\section{Las crisis de la psicología}

Se habla por último de las numerosas crisis que la psicología ha experimentado y continúa experimentando. ¿Por qué sucede esto? Ocurre en buena medida porque la psicología es una creación occidental, y Occidente es el escenario del surgimiento del capitalismo, fenómeno social que ha llevado al progreso experimentado por buena parte de la humanidad, pero que, para ese progreso se alcance, ha experimentado numerosas crisis de desarrollo, muchas de las cuales fueron vistas como terminales.

xiii Hasler (2014) señala que en el año 1968 aparecieron solo 2020 publicaciones sobre el cerebro, su estructura y funcionamiento; para 1988 esa cantidad se había elevado a 11770; y en el 2008 a 26500. 
Señalemos sin embargo que casi todas las ciencias, inclusive las exactas, han experimentado lo que podemos llamar crisis y aun hoy pueden verse envueltas en encendidas polémicas. Tomemos el caso de una de las ciencias exactas más prestigiadas, la física, que hacia fines del siglo XIX se desenvolvía en una atmósfera de crisis y de malestar (Heilbron 1982, Kragh 20 I 5). Los progresos experimentados por la física teórica en las primeras décadas del siglo $X X$, verdaderamente espectaculares, superaron la crisis que se cernía sobre esa ciencia.

\section{Tabla 5: Crisis en la historia de la psicología}

\begin{tabular}{|c|c|c|c|}
\hline Fecha & Suceso & Protagonistas & Consecuencias \\
\hline I 879 - Leipzig & $\begin{array}{l}\text { Surgimiento de la } \\
\text { psicología experimental }\end{array}$ & $\begin{array}{l}\text { Wilhelm Wundt (1832- } \\
\text { 1920) }\end{array}$ & $\begin{array}{l}\text { Proposición de la psicología } \\
\text { como ciencia y devaluación de la } \\
\text { llamada chair psychology. }\end{array}$ \\
\hline 1900 & 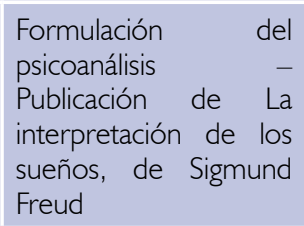 & Sigmund Freud & $\begin{array}{l}\text { Cuestionamiento de la } \\
\text { conciencia como el gran tema } \\
\text { de la psicología. Proposición del } \\
\text { inconsciente como el centro de } \\
\text { la vida psicológica. Rechazo del } \\
\text { método experimental }\end{array}$ \\
\hline 1913 & $\begin{array}{l}\text { Surgimiento del } \\
\text { conductismo con el } \\
\text { artículo "Psychology as } \\
\text { the behaviorist views } \\
\text { it", de John B. Watson, } \\
\text { Psychological Review, } \\
\text { 20, I58-177 }\end{array}$ & $\begin{array}{l}\text { John B. Watson (1878- } \\
\text { 1958) }\end{array}$ & $\begin{array}{l}\text { Proposición radical de una } \\
\text { psicología positivista, que } \\
\text { descarta a la conciencia y a los } \\
\text { procesos mentales y considera } \\
\text { como temas de estudio solo a los } \\
\text { aspectos visibles de la conducta } \\
\text { humana (el comportamiento) }\end{array}$ \\
\hline $1920-1930$ & $\begin{array}{l}\text { Discusiones acerca de } \\
\text { la crisis de la psicología } \\
\text { tanto en los Estados } \\
\text { Unidos como en } \\
\text { Europa }\end{array}$ & 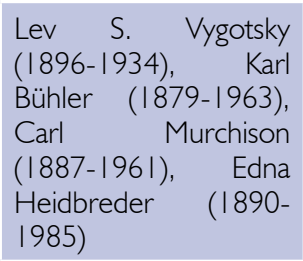 & $\begin{array}{l}\text { En particular Vygostky, desde } \\
\text { una perspectiva marxista, } \\
\text { cuestiona el saber psicológico } \\
\text { de su época y propone una } \\
\text { psicología vinculada a las ciencias } \\
\text { sociales, en particular a la historia }\end{array}$ \\
\hline 1960 & Revolución cognitiva & $\begin{array}{l}\text { Jean Piaget (I896- } \\
\text { 1980)y LevS. Vygotsky } \\
\text { (póstumamente) }\end{array}$ & $\begin{array}{l}\text { Redescubrimiento de la } \\
\text { conciencia }\end{array}$ \\
\hline 1960 & Psicología humanística & $\begin{array}{l}\text { Carl Rogers (1902- } \\
\text { 1987), Abraham } \\
\text { Maslow (1908-1970), } \\
\text { Charlotter Bühler } \\
\text { (1893-1974) }\end{array}$ & $\begin{array}{l}\text { Rechazo de las perspectivas } \\
\text { conductistas y psicoanalíticas } \\
\text { como las predominantes y } \\
\text { énfasis en los potenciales del } \\
\text { individuo }\end{array}$ \\
\hline 1990 & $\begin{array}{l}\text { Irrupción de las } \\
\text { neurociencias }\end{array}$ & $\begin{array}{l}\text { Michael Gazzaniga } \\
\text { (1939-), Paul (1942-) } \\
\text { y PatriciaChurchland } \\
\text { (1943-) }\end{array}$ & $\begin{array}{l}\text { Propuestas alternativas a la } \\
\text { psicología desde el mundo de } \\
\text { las neurociencias }\end{array}$ \\
\hline
\end{tabular}


En el caso de la física la crisis dio lugar a un avance sustantivo como acabamos de ver. En el caso de la psicología las cosas han ido por caminos diferentes, en buena medida porque su objeto de estudio es absolutamente distinto.

Un reputado economista, Joseph Schumpeter (1883-1950), gran estudioso del capitalismo, dijo que esta corriente consistía en una permanente "destrucción creativa" (creative destruction), que hace que formas de trabajo, comportamientos y herramientas útiles hasta ayer sean desechadas hoy en aras de una optimización de la producción y de un mayor rendimiento a un menor costo (McCraw 2007). El precio en términos humanos es sumamente elevado, por cierto.

¿Podría aplicarse ese concepto a lo que ocurre con las crisis que la psicología ha experimentado?

Cada crisis ha ido acompañada de una reflexión acerca de la naturaleza humana. La imagen del hombre en la Edad Media es diferente de la imagen del hombre en la Revolución Industrial y de la imagen del hombre en nuestros días, en que predomina la sociedad del conocimiento: la gran preocupación del hombre en la Edad Media estaba referida a su relación con Dios, en tanto que la gran preocupación del hombre de hoy es las posibilidades infinitas de desarrollo personal que él espera actualizar. Si Dios era una figura muy importante hace unos cinco o seis siglos, hoy, en una era secular, Dios es una figura secundaria.

En el caso de la psicología podemos observar con claridad los cambios en la imagen del hombre: se pasa de una concentración en la naturaleza humana como organismo receptor de estímulos (en la época de Wundt, cuando el gran tema de interés era la sensación y la percepción) a una visión casi trágica del hombre como es la de Freud, que destaca la importancia del inconsciente, de los instintos y de lo que sucede en la primera etapa de nuestra vida, y de allí se "salta" a una visión mecanicista (como la de Watson) en la que el hombre es casi una máquina de respuesta a estímulos. Hoy, compiten la imagen del hombre como un ser que analiza y elabora y reelabora los estímulos e impactos que recibe del medio ambiente (psicología cognitiva), con otra en la que el hombre aparece como un ser que aspira a estados de autoactualización (psicología positiva) y una tercera, en la que el ser humano reflexiona acerca de los aspectos insondables de su destino (psicología existencial). 


\section{Referencias}

Adorno, T. W., Frenkel-Brunswik, E., Levinson, D.J., Sanford, R. N. (1950). The Authoritarian Personality. New York: Norton

Berry, J. E. (20I2). Sigmund Freud, Arthur Schnitzler, and the birth of psychological man. Honors Theses, Paper 10 (Honors Theses presentada a la Faculty of the Departments of History and of German \& Russian Studies, Bates College http://scarab.bates.edu/cgi/viewcontent. cgi?article $=1067 \&$ context $=$ honorstheses; recuperado el 26.04.20 I6 .

Bilbeny, N. (1989). Kant y la Revolución Francesa. Refutación del derecho de resistencia civil. Anuario de Filosofía del Derecho, 6, 23-31.

Blom, Ph. (2007). Encyclopédie. El triunfo de la razón en tiempos irracionales. Barcelona: Anagrama.

Blom, Ph. (20। 0). A wicked company. The forgotten radicalism of the European Enlightenment. New York: Basic Books.

Bloom, H. (2008). Shakespeare. La invención de lo humano. Barcelona: Verticales debolsillo.

Blumenfeld, W. (1946). Introducción a la psicología experimental. Lima: Cultura Antártica.

Brinkmann, S. (201 I). Psychology as a moral science. Perspectives on normativity. New York: Springer.

Brozek, J. (1973). Psychologia of Marcus Marulus (I450- I 524). Evidence in printed works and estimated date of origin. Episteme, 7, |25-131.

Cassirer, E. (2007). Rousseau, Kant, Goethe: Filosofia y cultura en la Europa del Siglo de las Luces. Madrid: Fondo de Cultura Económica.

Cerdá, E. (1965). Una psicología de hoy. Barcelona: Herder.

Davidoff, L. (1989). Introducción a la psicología. México DF: McGraw Hill.

Delgado, H. ( 1969). Curso de psiquiatría. Barcelona: Científico-Médica.

Delgado, H. \& Iberico, M. ( 1933). Psicología. Lima: edición de los autores. 
De Vos, J. (20 I2). Psychologisation in times of globalization. Londres y New York: Routledge.

Dickens, Ch. (1972). Tiempos difíiles. Madrid: Alianza.

Durkheim, E. (2008). El suicidio. Madrid: Akal.

Eysenck, H. J. (1964). Psicología de la decisión política. Barcelona: Ariel.

Fleischhack, M. (20I5). Die Welt des Scherlock Holmes. Darmstadt: Lambert Schneider.

Gemelli, A. \& Zunini, G. ( 1 964). Introducción a la psicología. Barcelona: Miracle.

Goclenius, R., ed. ( 1590$)$. ЧҮХО АОГІА: hoc est, De hominis perfectione, animo et in primis ortu hujus, commentationes ac disputationes quorundam theologorum \& philosophorum nostrae aetatis [Psychology: that is, about human perfection, soul and in first place origin, and the comments of some of the discussions of the theologians and philosophers of our time]. Marpurgi Cattorum: Typis P. Egenolphi.

Hasler, F. (20 I4). Neuromythologie. Eine Streitschrift gegen die Deutungsmacht der Hirnforschung. Bielefeld: Transkript Verlag.

Heilbron, J. L. (1982) Fin-de-siècle physics. En: Bernhard, C. G.; Crawford, E. \& Sorbom, P., eds., Science, technology and society in the time of Alfred Nobel, Oxford - New York, Pergamon Press para Alfred Nobel Foundation, 5I-73.

Illouz, E. (2007). Intimidades congeladas. Las emociones en el capitalismo. Buenos Aires: Katz.

Jarochewski, M. (1975). Psychologie im 20. Jahrhundert. Berlín (República Democrática de Alemania): Volk und Wissen.

Kant, I. (2003). El conflicto de las facultades, en tres partes. Madrid: Alianza Editorial (original: 1798)

Kragh, H. (2015). The "new physics". En: Saler, M, ed., The fin-de-siècle world, Londres; Routledge, 44I-454.

Kundera, M. (1999). Teoría de la novela. Barcelona: Tusquets.

Legrenzi, P. \& Umiltà, C. (20I I). Neuromania. On the limits of brain science. Oxford: Oxford University Press. 
León, R. (20 I3). Jean Jacques Rousseau: un pensador para todas las estaciones. Acta Herediana, 53, 7I-76.

Massimi, M. ( 1983). Marcus Marulus, i suoi maestri e la "Psychologia de ratione animae humanae". Storia e critica della psicología, 4, 27-4I.

McCraw, Th. K. (2007). Prophet of innovation. Joseph Schumpeter and creative destruction. Cambridge, Mass.; Londres: The Belknap Press of Harvard University Press.

McReynolds, P. (1987). Lightner Witmer: little-know founder of clinical psychology, American Psychologist, 42 (9), 849-858.

Merari, A. (20।0). Driven to death. Psychological and social aspects of suicide terrorism. Oxford: Oxford University Press.

Oyebode, F., ed. (2009). Mindreadings. Literature and psychiatry. Londres: The Royal College of Psychiatrists.

Oyebode, F. (20/2). Madness at the theatre. Londres: The Royal College of Psychiatrists.

Papalia, D. E. \& Olds. S. B. (2000). Psicología. México DF: McGraw Hill.

Radin, P. (1973). El hombre primitivo como filósofo. Buenos Aires: EUDEBA.

Roudinesco, E. (20 I 5). Freud en su tiempo y en el nuestro. Barcelona: Debate

Russo Delgado, J. (1962). Lecciones de psicología general. Lima: Universidad Nacional Mayor de San Marcos.

Starobinski, J. (1983). Rousseau. La transparencia y el obstáculo. Madrid: Taurus.

Stockhorst, U.; Born, J. \& Kirsch, P. (20II). Psychologie nicht ohne Biologie. Antworten auf eine (rethorische?) Frage. Psychologische Rundschau, 62 (2), 116-119.

Tallis, R. (20 I I). Aping mankind: neuromania, darwinitis, and the misrepresentation of humanity. Londres: Acumen.

Vidal, F. (2006). Les sciences de I'âme. XVle-XVIIle siècle, Paris, Honoré Champion Éditeur. 
Whittaker, J. O. (1968). Psicología. México DF: Interamericana.

Winkler, H. A. (2009). Geschichte des Westens. Von den Anfängen in der Antike bis zum 20. Jahhundert. Munich: Beck.

Yalom, I. D. (1995). El día que Nietzsche lloró. Buenos Aires: Emecé.

Yalom, I. D. (2000). El don de la terapia. Carta abierta a una nueva generación de terapeutas y a sus pacientes. Buenos Aires: Emece.

Yalom, I. D. (20 I2). El enigma Spinoza. Buenos Aires: Emecé.

Wundt, W. ( 1 874). Grundzüge der physiologischen Psychologie. Leipzig: Engelmann. 